Vasconcelos of Mexico 
THIS PAGE INTENTIONALLY LEFT BLANK 
The Texas Pan American Series 


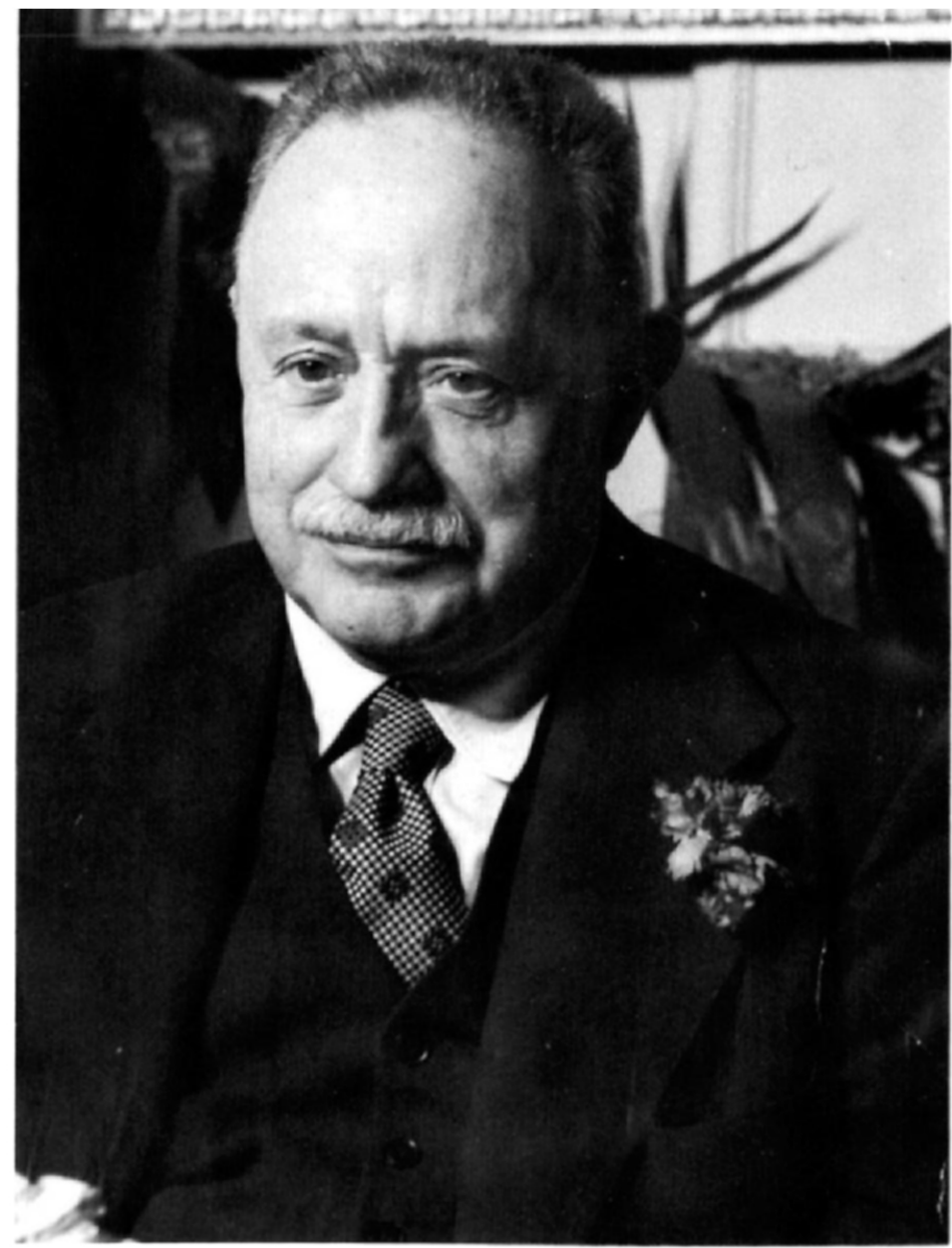

Bertha Hirsch.

José Vasconcelos, 1955 


\title{
Vasconcelos of Mexico PHILOSOPHER AND PROPHET
}

\author{
By John H. Haddox
}

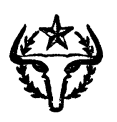

UNIVERSITY OF TEXAS PRESS, AUSTIN 
The Texas Pan American Series is published with the assistance of a revolving publication fund established by the Pan American Sulphur Company and other friends of Latin America in Texas.

Library of Congress Catalog Card No. 67-65612

Copyright (C) 1967 by John H. Haddox

All Rights Reserved

Printed in the United States of America

by the Printing Division of The University of Texas, Austin

Bound by Universal Bookbindery, Inc., San Antonio

ISBN 978-0-292-72171-5 (library e-book)

ISBN 978-0-292-72435-8 (individual e-book) 